\title{
A generic architecture for intelligent systems based on loT technology
}

\section{Une architecture générique pour les systèmes intelligents basés sur la technologie IdO}

\author{
Soheyb Ayad ${ }^{1}$, Labib Sadek Terrissa ${ }^{2}$ \\ ${ }^{1}$ Laboratoire d'Informatique Intelligente, Université de Biskra, Algérie, s.ayad@univ-biskra.dz \\ ${ }^{2}$ Laboratoire d'Informatique Intelligente, Université de Biskra, Algérie, terrissa@univ-biskra.dz
}

RÉSUMÉ. L'Internet des objets (IdO) est une technologie émergente dotée d'un potentiel énorme pour une applicabilité très large. L'IdO peut être défini comme un environnement omniprésent intelligent, basé sur une prolifération continue de réseaux intelligents, de capteurs sans fil et de centres de données gigantesques. L'idée de base de l'IdO est que pratiquement toutes les petites ou grandes choses physiques de ce monde peuvent être un ordinateur connecté à Internet. II existe de nombreux domaines de recherche sur la technologie IdO avec un grand nombre de domaines d'application.

Dans cet article, nous nous sommes intéressés aux systèmes intelligents basés sur la technologie IdO. Nous avons proposé une modèle de solution intelligente multi-locataire basée sur les technologies IdO et l'informatique en nuage, qui pousse les systèmes classiques (agricoles, santé ou industriels) à être connectés, et enrichie d'un système centralisé dans le nuage offrant une application Web (tableau de bord) permettant de surveiller, superviser et contrôler un nombre important d'objets (machine ou homme) géographiquement séparés. Dans ce travail, nous proposons une solution générique basée sur la technologie IdO pour les systèmes intelligents dont nous avons testé sur deux cas d'études (agriculture et industrie).

ABSTRACT. The Internet of Things (IOT) is an emerging technology with a huge potential for a very wide applicability. "IOT can be defined as an intelligent pervasive environment, based on a continuing proliferation of intelligent networks, wireless sensors and a massive data centers; the basic idea of IOT is that, virtually every small or large physical thing in this world can be a computer connected to the Internet. There are many fields of research on loT technology with a wide number of application domains".

In this paper, we had interested to smart systems based on loT technology. We have proposed a new smart multitenant solution based on IOT and cloud computing technologies which push classic systems (agricultural, healthcare or industrial) to be connected, and enhanced with a system offering a Web Application (Dashboard) to monitor, supervise and control an important number of objects (machine or human) geographically separated. In this paper, we propose an IoT based generic solution for smart systems and we have implemented and tested it on two study cases (Agriculture, industy).

MOTS-CLÉS. Internet des Objets (IdO), Informatique en Nuage, Agriculture Intelligente, Industrie Intelligente, Santé Intelligente, Protocole MQTT, Supervision, Sontrôle à distance.

KEYWORDS. Internet of Things (IOT), Cloud Computing, Smart agriculture, Smart manufacturing, smart healthcare, MQTT Protocol, Monitoring; Remote Control.

\section{Introduction}

The Internet of Things is a computing concept that describes the idea of everyday physical objects being connected to the internet and being able to identify themselves to each other. Some of the worldwide leaders in information technologies like Cisco, claims that Internet of Things will change everything including ourselves, and justify their statement by mentioning the impact that the Internet already has had on education, communication, business, science, government, and humanity. IoT can be defined also as "A global, invisible, ambient networked computing environment built through the continued proliferation of smart sensors, cameras, software, databases, and massive data centers in a world-spanning information fabric the basic idea of the loT is that virtually every physical thing in this world can also become a computer that is connected to the Internet". IoT currently is one of the most 
interesting topics in information and communication technology that it has many visions and can be applied in almost any domain [SAL 18a].

"Industry 4.0 creates what has been called a " smart factory Within the modular structured smart factories, cyber-physical systems monitor physical processes, create a virtual copy of the physical world and make decentralized decisions. Over the Internet of Things, cyber-physical systems communicate and cooperate with each other and with humans in real time, and via the Internet of Services, both internal and crossorganizational services are offered and used by participants of the value chain".

(sites : http://www.control-infotech.com/industrie.html, https://www.microtom.com/solutions/industry$\underline{4-0})$

In agriculture domain, farmers maintain each of their greenhouses physically and cannot know their status without physically visiting and manually maintaining them one by one. Due to the huge number of greenhouses the farmers will not be able to well perform their duty and may ignore some of the important tasks like sufficient irrigation, necessary aeration, controlling temperature and humidity which can affect the quality and the quantity of crops.

Also, "the internet of things has numerous applications in healthcare, from remote monitoring to smart sensors and medical device integration. It has the potential to not only keep patients safe and healthy, but to improve how physicians deliver care as well. Healthcare IoT can also boost patient engagement and satisfaction by allowing patients to spend more time interacting with their doctors " (https://searchhealthit.techtarget.com/essentialguide/A-guide-to-healthcare-IoT-possibilities-andobstacles)

In this work we have proposed an IoT based generic adaptive solution in order to push classic environment systems (Agriculture, healthcare and manufacturing) to a smart connected environment using IoT and cloud computing concepts. This solution has been implemented and tested.

\section{Related Work}

There are many research fields on IoT technology with a wide number of domains and subjects; some researchers were focused on the use of IoT to monitor environments, other works are interested on IoT architecture, security, privacy and even the communication protocols [SAL 18b].

In [ZAM 15], the authors have proposed an IoT Monitoring System for School Transport, they have used a micro-controller in each scholar bus equipped with localization and speed sensors, they installed in it a publisher client; the connection to a central Broker Server is established with GPRS and MQTT (Message Queuing Telemetry Transport) [CLA 18] protocols. The authors also have proposed an Android application and PaaS (Platform as a Service) to implement a MQTT clients for subscribers. They used also Google maps API(Application Programming Interface). The authors aim was to allow many stakeholders (subscribed with central Broker) such as parents, the government, the schools responsible and many other authorities to keep in real-time track of the scholar bus behavior, resulting in a better controlled scholar bus in order to achieve a safer school transport for children.

The authors in [SHR 16] have proposed an IoT monitoring system for solar Photovoltaic Power Conditioning Unit (PVPCU) based on IoT three layer architecture. This system had incorporated remote monitoring for solar PV PCU to allow management of maintenance problems.

The work in [ZHA 16] presents an online monitoring system based on IoT architecture which is composed of four layers: sensing, network, service resource, and application layers. It integrates various data processing techniques including protocol conversion, data filtering, and data conversion. The proposed system has been implemented and demonstrated through a real continuous steel casting production line, and integrated with the TeamCenter platform. The aim of the authors is monitoring the (C) 2019 ISTE OpenScience - Published by ISTE Ltd. London, UK - openscience.fr 
environment conditions and the working status in order to achieve accurate failure prediction, timely repair, and maintenance of the equipment.

Authors in [ALF 15] proposed an intelligent IoT protocol gateway to address the problem of horizontal integration between protocols, they provided an hybrid architecture based on MQTT protocol that would allow it to operate in M2M (Machine to Machine) as well as M2S (Machine to server) and S2S (Server to Server) scenarios. They have also improved it in order to support rich QoS features.

In [SIN 15] the authors are focused on the security part of devices and D2D (Device to Device) communication. They have proposed a SMQTT protocol which augments security feature to the existing MQTT. To do that, they have implemented a new MQTT Publish Message named Spublish (S: Secure); this new secure MQTT Publish message encrypt the payload in MQTT header with ABE (Attribute Based Encryption) based on lightweight (Elliptic Curve Cryptography). They state that the advantage of using $\mathrm{ABE}$ is its broadcast encryption mechanism, which means that one encryption message can be delivered to multiple intended users; this option is suitable for IoT applications.

The Authors in [CAP 15] explained the need of an optimized IoT protocols, adapted to the constrained devices, because in the current implementations there is a high energy consumption and a long data delevry delays which limits their effective use in real-life deployments, to deal with that challenges the authors have proposed a solution integrating the DTLS protocol inside the Constrained Application Protocol (CoAP) [RFC 18].

\section{Discussion}

Our study of related work presented above, leads us to say that any IoT solution should ensure the following points :

- A system to supervise or to monitor in real-time our environment to get detailed information about its status, in order to choose which decision to make.

- Choosing the appropriate architecture layers [SET 17] according to the system functionality.

- Selecting the appropriate communication protocol for the proposed architecture.

- Securing the information to keep them safe from hacking (stealing, data corruption ... etc).

In Table 1we have classified and compared the studied works according to some metrics needed for an IoT solution. 


\begin{tabular}{|c|c|c|c|c|c|c|c|}
\hline Work Title & Topic & IoT Protocol & $\begin{array}{c}\text { Sensors } \\
\text { Type }\end{array}$ & Security & $\begin{array}{c}\text { Layer } \\
\text { Architecture } \\
\text { Supported }\end{array}$ & $\begin{array}{l}\text { Intern- } \\
\text { et } \\
\text { Access }\end{array}$ & $\begin{array}{c}\text { Cloud } \\
\text { Computing } \\
\text { Solution }\end{array}$ \\
\hline $\begin{array}{c}\text { An IoT based } \\
\text { scholar bus } \\
\text { monitoring system } \\
\text { [ZAM 15] }\end{array}$ & Monitoring & MQTT & $\begin{array}{c}\text { Location+ } \\
\text { Speed }\end{array}$ & - & 3 & GPRS & $\begin{array}{c}\text { PaaS+Cloud } \\
\text { Broker }\end{array}$ \\
\hline $\begin{array}{c}\text { A Smart IoT } \\
\text { System For } \\
\text { Monitoring Solar } \\
\text { PV Power } \\
\text { Conditioning Unit } \\
\text { [SHR 16] }\end{array}$ & Monitoring & - & $\begin{array}{l}\text { Power } \\
\text { and } \\
\text { Energy }\end{array}$ & - & 3 & GPRS & PaaS \\
\hline $\begin{array}{c}\text { An IoT Based } \\
\text { Online Monitoring } \\
\text { System for } \\
\text { Continuous Steel } \\
\text { Casting [ZHA 16] }\end{array}$ & Monitoring & Modbus-TCP & $\begin{array}{c}\text { Temperat } \\
\text { ure }+ \\
\text { Presure }+ \\
\text { Roller } \\
\text { Speed } \\
\end{array}$ & - & 4 & G-GPR & - \\
\hline $\begin{array}{c}\text { Toward Better } \\
\text { Horizontal } \\
\text { Integration Among } \\
\text { IoT Services [ALF } \\
\text { 15] }\end{array}$ & $\begin{array}{c}\text { IoT } \\
\text { Protocols } \\
\text { Gateway }\end{array}$ & MQTT & - & - & All & - & - \\
\hline $\begin{array}{c}\text { Secure MQTT for } \\
\text { Internet of Things } \\
\text { (IoT) [SIN 15] }\end{array}$ & $\begin{array}{l}\text { Adding } \\
\text { security } \\
\text { to MQTT }\end{array}$ & MQTT & - & $\begin{array}{c}\mathrm{AB} \\
\text { Encryptio } \\
\mathrm{n}\end{array}$ & ALL & - & - \\
\hline $\begin{array}{c}\text { Security as a CoAP } \\
\text { resource: an } \\
\text { optimized DTLS } \\
\text { implementation } \\
\text { for the IoT[CAP } \\
15]\end{array}$ & $\begin{array}{l}\text { DLTS and } \\
\text { CoAP } \\
\text { Combination } \\
\text { and } \\
\text { Optimisation }\end{array}$ & CoAP & - & DLTS & All & - & - \\
\hline
\end{tabular}

Tableau 1. Comparainson between loT related work

\section{Proposed Architeture Description}

In this study, We have proposed a new generic smart solution based on IoT and cloud computing technologies in order to give the ability to monitor and to control connected devices which can be industrial (machines), agricultural (greenhouses) and medical (blood pressure) without the need to intervene each time to make regular actions.

The importance of such a system become clearly necessary when dealing with a considerable number of distributed objects to monitor.

As illustrated in Figure 1, our proposed architecture is composed of three principal parts which are: 


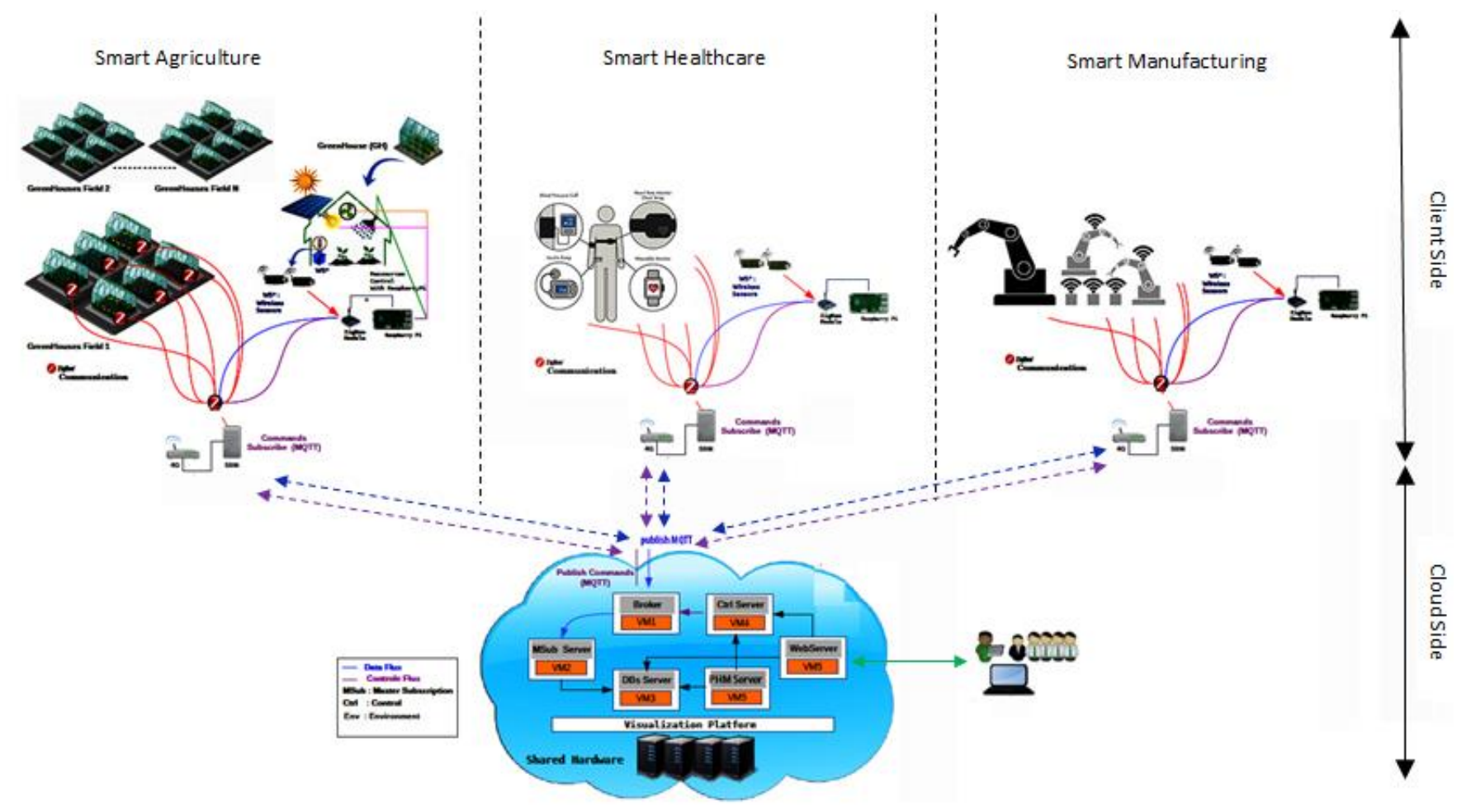

Figure 1. Proposed Solution Architecture

Client-Side: represents the monitored devices or assets and the used equipment in order to connect and to communicate them with clous processing System.

Cloud Processing System (CP System): represents our proposed six cloud servers which are dedicated to collect the received data from the asset sensors, also to control remotly these assets.

Cloud Environment (CE): is the cloud computing infrastructure in which cloud processing system is hosted; it also represents the classic cloud computing environment.

\subsection{Client-Side}

\subsubsection{Principal Components}

In order to connect each Asset we needed the $C_{n}$ electronic components presented in Table 2 . 


\begin{tabular}{|c|c|}
\hline Component Cn & Description \\
\hline Sensors & $\begin{array}{c}\text { Light sensor, Temperature } \\
\text { sensor and Humidity sensor }\end{array}$ \\
\hline Principal Sink & Connect all the intermediate sinks to Internet \\
\hline $\begin{array}{c}\text { Intermediate Sink or Microcontroller } \\
\text { (Raspberry Pi + ZigBee) }\end{array}$ & $\begin{array}{c}\text { Connect and manage all sensors } \\
\text { and actuators }\end{array}$ \\
\hline Gateway & LTE router (G4/3G): connect \\
the farm to the Internet
\end{tabular}

Tableau 2. Client-Side Components

\subsubsection{Deployment and Functionality}

The presented client-side components are deploying as follow:

- We have placed the wireless sensors within each assets or devices

- Intermediate Sink (Micro-controller: Raspberry Pi) [BRA 18]: it has two tasks, the first one is gathering environment data from wireless sensors before sending them over ZigBee communication to the principal sink; the second task is controlling the Actuators with GPIO (General Purpose Input Output) board and relay module.

- Principal Sink (Sink Server): It has also two tasks; the first one is to collect data from the intermediate sinks and to send them using the MQTT protocol to the Cloud Processing System. The second task is receiving the control commands from Cloud Processing Systems ystem and retransmitting them to the appropriate intermediate sink.

- The Gateway: $3 \mathrm{G} / 4 \mathrm{G}$ wireless technologies connected to the principal sink.

- Energy source: using solar panels.

- Scripts: We have implemented and deployed 4 principal scripts in the Client-Side; we will explain these scripts in the following pseudo-algorithms.

In order to collect data from sensors, the next algorithm (Algorithm 1) is deployed on the intermediate sink

\section{Algorithm 1 Collect Data \\ while running $\underline{d o}$ sensing data (Mi) \\ send to principal sink (Mi) \\ end while}

Where Mi represents a message which contain the asset or device Identifier, Sensor Identifier, Sensed Data, and the Sending Time.

The second script (Algorithm 2) deployed on the intermediate sink allows the commands receptions from the principal sink in order to control the actuators. 
Algorithm 2 Receive Commands

while running $\underline{d o}$

receive commands from principal $\operatorname{sink}(T i)$

$A k=\operatorname{select}$ action $(T i)$

end while

run actuators $(A k)$

Where Ti represents the command to execute in the GHi, it contains asset or device Identifier, Actuator Identifier, Action Ak to do and the Sending Time.

The third algorithm (Algorithm 3) is deployed on the principal sink to collect data (Mi) from the intermediate sink and publish it as a Broker MQTT publisher in the cloud processing system.

Algorithm 3 receive $(\mathrm{Mi})$

while running $\underline{\text { do }}$

topic $=$ generate topic $(\mathrm{Mi})$

end while

MQTT.publish(topic, broker network address)

The last Client-Side script (Algorithm 4) is deployed on the principal sink to receive commands from Cloud processing system and sending them to the target intermediate sink.

Algorithm 4 receive (MQTT subscriber topic)

while running $\underline{d o}$

$T i=$ generate command message (MQTT subscriber topic).

send to intermediate Sink(Ti);

end while

\subsection{Cloud processing System (Cloud Provider-Side)}

\subsubsection{Principal components}

In order to manage efficiently the functionality of the proposed solution, we have separated our proposed Cloud processing system into six Virtual Machines (VMs) servers (roles), which are presented in Table 3. 


\begin{tabular}{|c|c|}
\hline MQTT Broker Server & $\begin{array}{l}\text { It has two roles: monitoring and Remote control management. } \\
\text { 1) Monitoring: receive MQTT publisher messages from the Principal } \\
\text { Sink and sending them to MSub Server which manages and affect them to the appropriate } \\
\text { subscriber client. } \\
\text { 2) Remote command: receive control messages from the Control Server and distribute them } \\
\text { as MQTT publisher messages to the appropriate Principal Sink subscribers. }\end{array}$ \\
\hline $\begin{array}{c}\text { Master Subscription } \\
\text { Server (MSub Server) }\end{array}$ & Manage all MQTT messages types and save data over the the Databases Server. \\
\hline $\begin{array}{c}\text { Databases Server (DBs } \\
\text { Server) }\end{array}$ & Save and manage data of MSub Server, AD Server, and Web Server. \\
\hline Web Server & Used to host our developed cloud SaaS. \\
\hline Control Server (CtrlServer) & $\begin{array}{l}\text { Receives user commands sent through our proposed SaaS (Software as a Service) web } \\
\text { interface (Web Server) as a manual control, also the automatic commands sent from the } \\
\text { Auto Decision Server, after that the Control Server publish the commands as MQTT } \\
\text { messages through the Broker Server to the destined Principal Sink. }\end{array}$ \\
\hline $\begin{array}{l}\text { Automatic Decision } \\
\text { Server (AD Server) }\end{array}$ & $\begin{array}{l}\text { Responsible of making automatic decision, to minimize the need of repetitive user } \\
\text { intervention and can be pre-configured to satisfy the } \\
\text { needed actions of connected objects. }\end{array}$ \\
\hline
\end{tabular}

Tableau 3. Intelligent Systems Components

\section{Implementations and Case studies}

In order to implement our generic architecture, we have chosen two strategic fields that are the agriculture (smart greenhouses) and industry (smart manufacturing). The assets in the both cases are respectively Greenhouses and machine. We have used several hardware and software tools which are:

\subsection{Hardware tools}

- Sink (Advanticsys SG1000): is an 802.15.4 Ethernet gateway device that acts as data concentrator for wireless sensor networks. [ADV 18]

- Wireless sensors (MAXFOR XM1000): new generation of mote (sensors) modules, based on TelosB"technical specifications. [WIR 18]

- Raspberry Pi 3 Model B: is a credit card-sized computer. Due to its small size and accessible price; it was quickly adopted by tinkerers, makers, and electronics enthusiasts for projects that require more than a basic microcontroller (such as Arduino devices).

- Sainsmart 4-Channel 5V Relay Module: is a 5V 4Channel Relay interface board, which able to control various appliances, and large current equipment. It can be controlled directly by Micro-controller (Raspberry Pi, Arduino, 8051, AVR, PIC, DSP, ARM, ARM, MSP430, TTL logic etc). [SAI 18]

- Cloud Computing Platform: we have hosted our Greenhouses/machine System in a Cloud Computing environment of Synchromedia Laboratory [SYN 18] in order to get best results. 
- Python as our programming language since it has a wide collection of frameworks.

- Open source Eclipse Mosquitto broker, which implements the MQTT protocol that provides methods of carrying out messaging using a publish/subscribe model; this makes it suitable for Internet of Things messaging for such low power sensors or mobile devices like smartphones, embedded computers or microcontrollers (Arduino, Raspberry ...etc). [ECL 18]

- Python Paho-MQTT: this package provides a client class which enable applications to connect to an MQTT broker to publish messages to subscribe to topics and to receive published messages. [LIG 18]

- Python Cryptography Toolkit: is a collection of cryptographic algorithms and protocols including both secure hash functions (such as SHA256 and RIPEMD160), and various encryption algorithms (AES, DES, RSA, ElGamal, etc.). We have used AES through this package in order to secure our MQTT messages.

- Web.py: is a web framework for Python.

- Python Dataset: toolkits that provide a simple abstraction layer for database access; it removes most direct SQL statements without the necessity for a full ORM model. Essentially, the databases can be used like a JSON file or NoSQL store. Database contents can be exported using a sophisticated plain file generator with JSON and CSV support. Exports can be configured to include metadata and dynamic file names depending on the exported data. The exporter can also be used as a command-line tool, datafreeze. [WEH 18]

- Corona SDK [COR 18]: is a framework that empowers developers to create 2D games and apps for mobile, TV, and desktop. It has the ability to generate apps for smartphone systems like android and iOS by using the same source code. We have used corona SDK in order to develop an android App for our web App.

- Monitoring dashboard: it represents the developed web application (SaaS) which allow clients to both supervising and controlling.

- Our Solution offers also android applications where the clients can supervise and control their systems over smartphones.

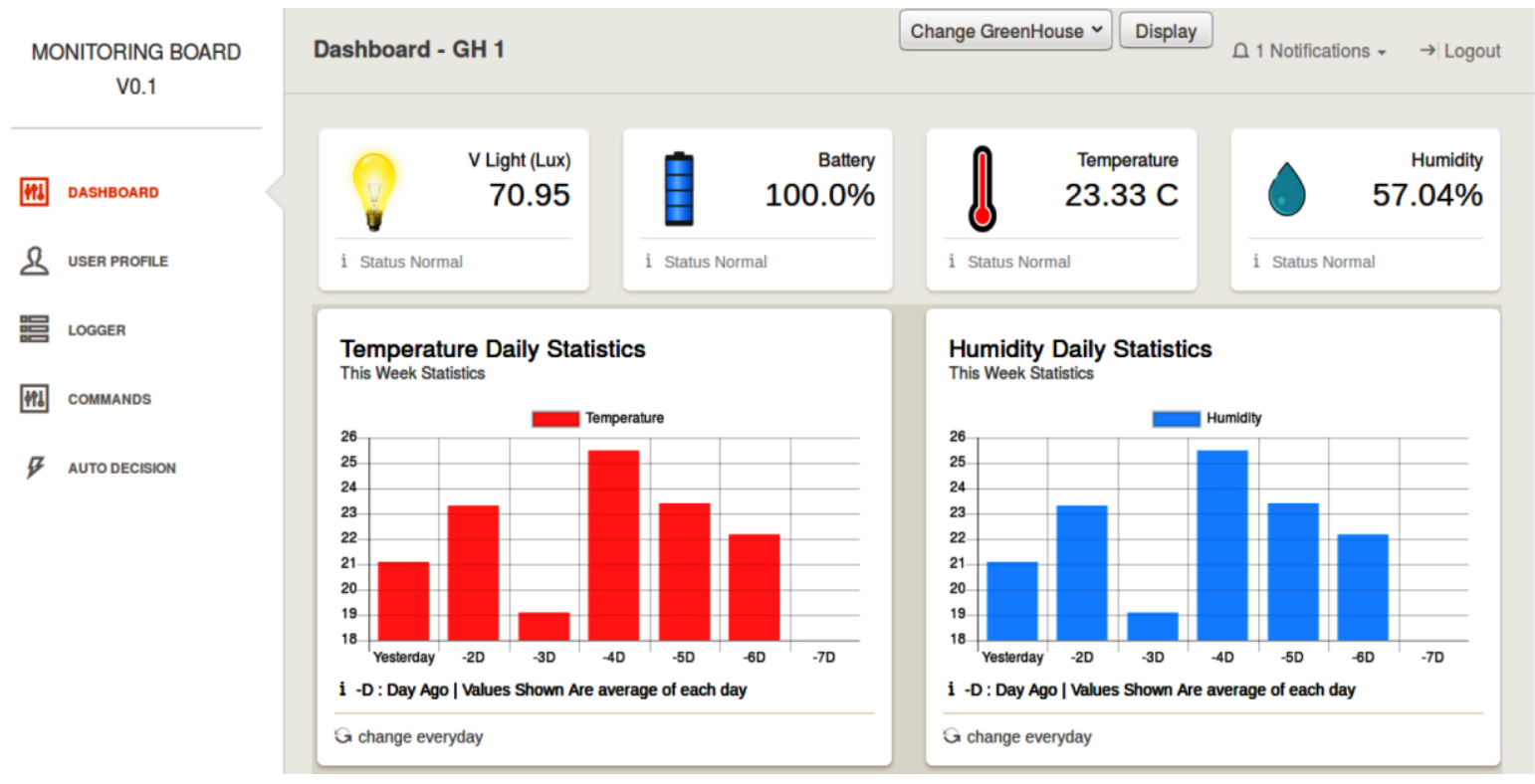

Figure 2. Greenhouse SaaS interface 


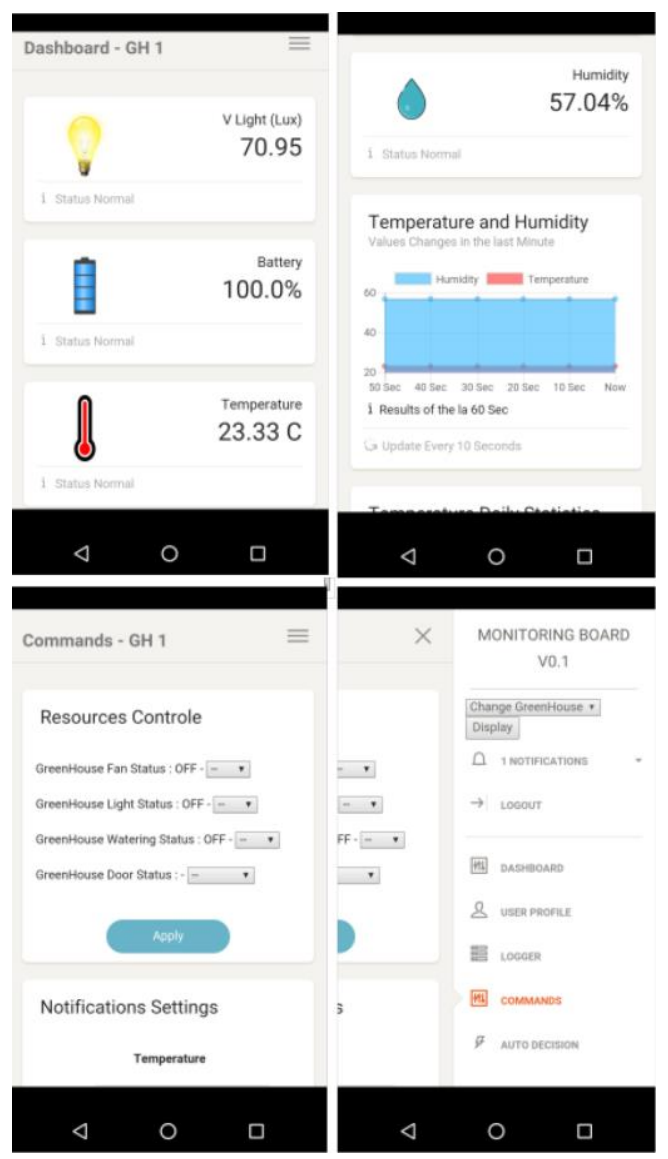

Figure 3. Android's greenhouse dashboard application

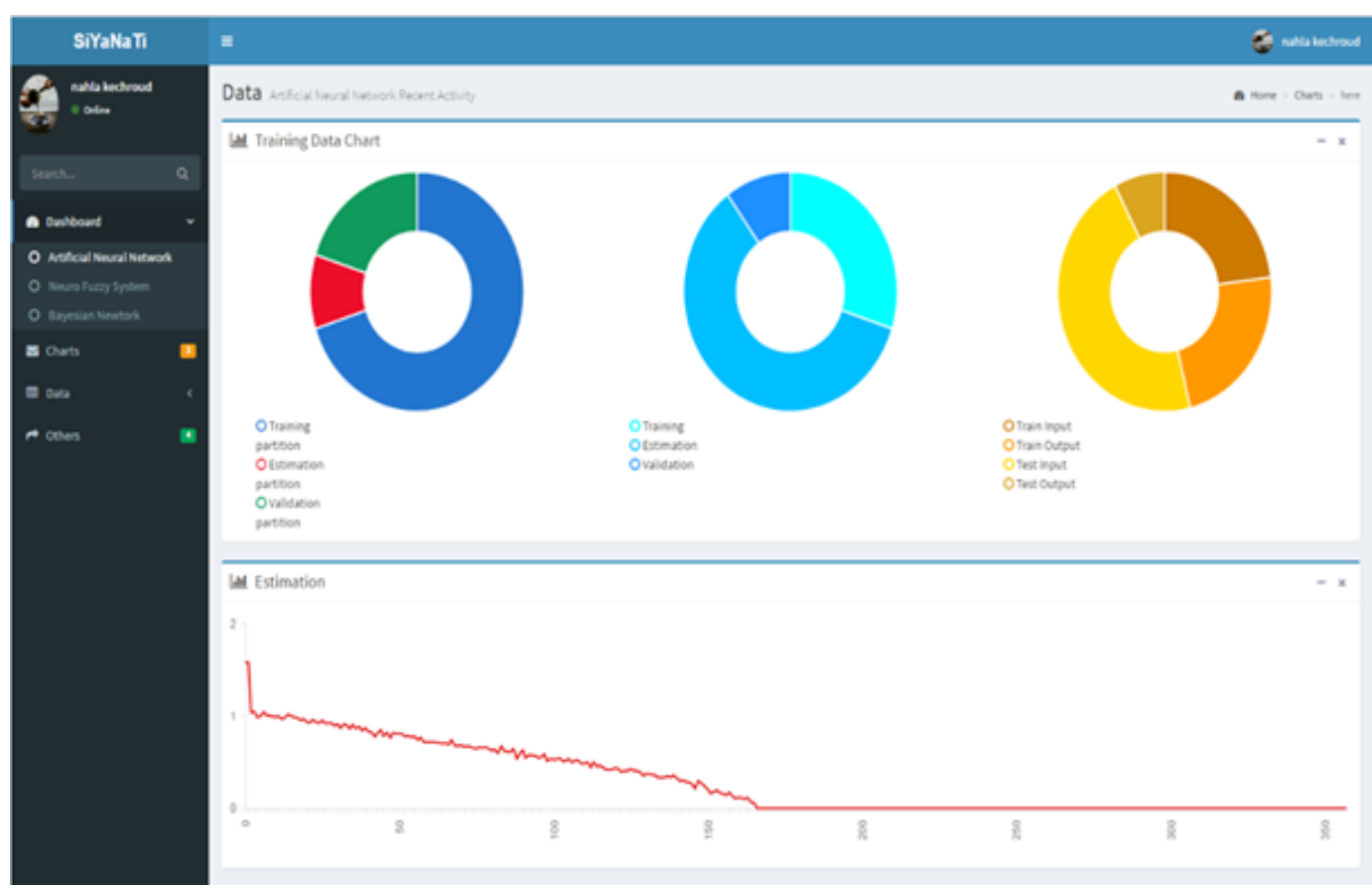

Figure 6. Industry dashboard (SiYaNaTi)

\section{Conclusion}

The Internet of Things has been growing at an increasing rate leading to an important revolution in industry, environment and society which presents a huge impact that will change human life. Despite the challenges that may face this technology such as security, privacy and horizontal integration between services, this has not stopped its expansion in contrast factors such as the cheap cost of 
equipment (like sensors and microcontrollers ... etc). Furthermore, the support of the open source community in the form of open standards and libraries has given a boost to this technology.

In this paper, we have designed and implemented a new smart multitenant solution based on IoT and Cloud Computing technologies for smart greenhouses, smart healthcare and smart industry domains. This solution offers cloud services in order to monitor, and to control remotely their every connected object any time and everywhere. Beside this, it resolves efficiently the management problem of big number of the connected objects through the presented SaaS. Actually, we are performing and adapting this solution to healthcare field. As perspective, we are studying the possibility to add Artificial Intelligence to develop cloud machine learning algorithm which learn in a real time about the status of connected objects in order to execute an automatic optimized decisions.

\section{References}

[ZAM 15] J. ZAMBADA, R. QUINTERO, R. ISIJARA, R. GALEANA AND L. SANTILlAN, "An IoT based scholar bus monitoring system”, IEEE First International Smart Cities Conference (ISC2), Guadalajara, Mexico, 2015.

[SHR 16] B. SHRIHARIPRASATH AND V. RATHINASABAPATHY, "A smart IoT system for monitoring solar PV power conditioning unit", IEEE World Conference on Futuristic Trends in Research and Innovation for Social Welfare (Startup Conclave), Coimbatore, India, 2016.

[ZHA 16] F. ZhANG, M. LIU, Z. ZHOU, W. SHEN, “An IoT-Based Online Monitoring System for Continuous Steel Casting", IEEE Internet of Things Journal, 2016.

[ALF 15] A. Al-FuQAHA, A. Khreishah, M. GuIZANI, A. RAYES, M. MohAmMADI, "Toward better horizontal integration among IoT services", IEEE Communication Magazine, 2015.

[SIN 15] M. Singh, M.A. RAJAN, V.L. SHIVRAJ AND P. BALAMURALIDHAR, "Secure MQTT for internet of things (IoT)", IEEE Fifth International Conference on Communication Systems and Network Technologies (CSNT), 2015.

[CAP 15] A. Capossele, V. Cervo, G.D. Cicco, C. Petrioli, "Security as a CoAP resource: an optimized DTlS implementation for the IoT", IEEE International Conference on Communications (ICC), London, UK, 2015.

[SAI 18] Sainsmart, “4-Channel 5V Relay Module”. [online], Available: https://www.sainsmart.com/products/4-channel5v-relay-module.

[SAL 18a] SALEH I., "Les enjeux et les défis de l'Internet des Objets (IdO)". Revue Internet des objets. 17. 10.21494/ISTE.OP.2017.0133.

[SAL 18b] I SAlEH, M. AMMI \& S. Szoniecky «Challenges of the Internet of Things: Technology, Use, Ethics », Copublisher ISTE \& Wiley Editions, Londres, 2018, ISBN : 9781786303615.

[LIG 18] R. LIGHT, “Python MQTT Client”. [online]. Available: https://eclipse.org/paho/clients/python/.

[COR 18] CORONA LABS, “Cross-Platform Mobile Game/App Development Toolset”. [online]. Available: https://coronalabs.com/.

[CLA 18] A.S. CLARK AND A. NIPPER, "MQTT (MQ Telemetry Transport), IBM and Arcom". [online]. Available: http://mqtt.org/

[RFC 18] RFC 7252, CoAP (The Constrained Application Protocol). [online]. Available: http://coap.technology/

[SYN 18] SYNCHROMEDIA, Laboratory for multimedia communication in telepresence. Quebec, Canada. [online]. Available: http://www.synchromedia.ca/

[ECL 18] THE ECliPse Foundation, Mosquitto An Open Source MQTT Broker. [online]. Available: https://mosquitto.org/

[WEH 18] S. WEHRMEYER, F. LINDENBERG, G. Aisch, Python Dataset. [online]. Available: http://github.com/pudo/dataset.

[ADV 18] AdvanTICSYS, SG1000 Data Concentrator. [online]. Available: https://www.advanticsys.com/wiki/.

[WIR 18] WIRELESS SENSORS. Korea. [online]. Available: http://www.maxfor.co.kr

[BRA 18] D. BRABEN, Raspberry Pi. [online]. Available: https://www.raspberrypi.org/ 
[SET 17] P. SETHI AND S.R. SARANGI, "Internet of Things: Architectures, Protocols, and Applications", Journal of Electrical and Computer Engineering, 2017. 